University of St. Thomas, Minnesota

UST Research Online

2009

\title{
African Americans and Recovery from Severe Mental Illness
}

David J. Roseborough

University of St. Thomas, Minnesota, djroseboroug@stthomas.edu

William Bradshaw

University of Minnesota - Twin Cities

Marilyn Peterson Armour

University of Texas at Austin

Follow this and additional works at: https://ir.stthomas.edu/ssw_pub

Part of the Clinical and Medical Social Work Commons, Psychology Commons, and the Social Work Commons

This Article is brought to you for free and open access by the School of Social Work at UST Research Online. It has been accepted for inclusion in Social Work Faculty/Staff Publications by an authorized administrator of UST

Research Online. For more information, please contact asle4660@stthomas.edu. 


\section{African Americans and Recovery from Severe Mental Illness}

Marilyn Armour, Ph.D.

University of Texas at Austin

William Bradshaw, Ph.D.

University of Minnesota

David Roseborough, Ph.D.

University of St. Thomas 


\begin{abstract}
This mixed methods study examined the lived experience of African American persons recovering from serious and persistent mental illness (SPMI) and assessed changes in demoralization, engulfment and coping over time. Psychological measures were administered and semi-structured interviews were conducted at three time points $(6$, 12, and 18 months) with nine African Americans with SPMI. Qualitative analysis was done from an Afrocentric perspective. The interviews were transcribed, read and coded to cluster thematic aspects in each case and across cases. Atlas-ti was used to recode transcripts and retrieve quotes to dimensionalize each essential theme. Four themes were identified: 1) striving for normalcy, 2) striving for a positive and proactive outlook, 3) mastering the challenges posed by mental illness, and 4) leaning on the supports that watch out for and over me. Paired $t$-tests were performed on the dependent variables of demoralization, coping, and engulfment. There was a significant change in reduction of demoralization and increase in coping from Time 1 to Time 2 . There was no significant change in engulfment. These changes are noteworthy as participants averaged 21 years of illness. The relationship between the quantitative results and qualitative findings are discussed. Results have implications for practice and improving recovery-oriented services to African Americans. For example, case managers are advised to consider mental health stigma and anti stigma interventions that are inclusive of racial discrimination and expand their cultural sensitivity to include the sense of endangerment experienced by African American clients. Four African American consultants critiqued the study anonymously.
\end{abstract}


A report by the U.S. Surgeon General (U.S. Department of Health and Human Services, 1999) and another by the President's New Freedom Commission on Mental Health (U.S. Department of Health and Human Services, 2003) identifies recovery as a guiding principle in the provision of mental health services. Recovery refers both to internal conditions - the attitudes, experiences and processes of change of individuals who are recovering — and external conditions — the circumstances, events, policies and practices that may facilitate recovery (Jacobson \& Greenley, 2001). Although it has emerged as a new paradigm that is influencing practice and policy related to severe and persistent mental illness (SPMI), e.g. State of Wisconsin Blue Ribbon Commission on Mental Health (1997), literature on the recovery process and community based rehabilitation services have rarely investigated factors related to race or ethnicity. Phillips and colleagues (2001) suggest that limited attention to cross cultural issues is related to the commonly held belief that the experience of severe mental illness supersedes any particular cultural or ethnic identification.

Studies on psychosocial rehabilitation that have addressed the influence of race and ethnicity have focused on intervention outcomes (e.g. Baker, Tokes-Thompson, Davis, Gonzo, \& Hishinuma, 1999; Phillips, Barrio \& Brekke, 2001; Sung-Woo Bae, Brekke and Bola, 2004; Telles et al., 1995). For example, Telles et al. compared culturally-modified, behavioral family management (BFM) and case management in a sample of low-income Latino schizophrenia patients. Levels of patient acculturation were found to be significantly related to various measures of treatment outcome; among less acculturated patients BFM was significantly related to greater risk of exacerbation of 
symptoms. Baker et al. found positive outcomes for African Americans participating in an intensive program based on an assertive community treatment model. Phillips et al. found significant differences among non-minorities, African Americans and Latinos in rehabilitative change over three years in the domains of work and social functioning. Non-minorities gained in social and work functioning. African Americans showed little change in social functioning and African Americans and Latinos showed a decline in work functioning. Bae et al. examined cross-ethnic treatment outcome variation in persons with schizophrenia. With the exception of slower social improvement for African Americans, Whites, Latinos, and African Americans showed similar change trajectories. These disparate findings suggest the need for more studies on the subjective experience of recovery from a racial or ethnic perspective in order to identify culturally relevant dimensions for study and intervention development.

A limited number of studies have examined the subjective experience of persons with severe and persistent mental illness in recovery (e.g. Estroff, 1989; Davidson \& Strauss, 1992; Bradshaw, Roseborough \& Armour, in press). Of these studies, few of them have focused directly on the recovery process for African Americans. Estroff examined self labeling and illness explanations in a sample of Whites and African Americans. African American women self labeled consistently as mentally ill at a much higher rate than African American men who were more likely to be involuntary patients and have a higher prevalence of the diagnosis of schizophrenia. This finding is important because studies of severe mental illness consistently show that poorer outcomes are related to engulfment in a disease identity and demoralization (e.g. McCay \& Seeman). Moreover demoralization reduces a person's adaptive coping processes (Lysaker, 
Campbell, Kikuko, \& Johannesen, 2005). In a four-year study of recovery processes, Spaniol, Wewiorski, Gagne \& Anthony, (2002) found that the African American participants in a mixed white, African American and Asian sample experienced the double stigma of race and mental illness and commonly confronted substance abuse and poverty in their own lives and lives of those around them. Other studies have used samples that include African Americans (e.g. Davidson et al., 2001; Chiman, 1999; Williams, 1999) but the findings did not delineate differences by race and ethnicity. The purpose of this mixed methods study is to 1) better understand the lived experience of recovery for African American persons with SPMI, 2) assess changes in demoralization, engulfment and coping over time, and 3) examine how quantitative and qualitative findings inform each other.

\section{Methods}

\section{$\underline{\text { Sample }}$}

African American participants ( $\mathrm{n}=9$ ) were recruited from Mental Health Resources, Inc. (MHR), a non-profit mental health provider of services to persons with SPMI located in the upper Midwest. Services included assertive community mental health treatment teams and less intensive case management services. Inclusion criteria for the study were 1) a diagnosis of schizophrenia, schizoaffective, bipolar, chronic major depression and substance abuse; 2) involvement in MHR for 4 months or less; and 3) no evidence of a primary substance dependence diagnosis or organic brain syndrome. Informed consent was obtained from the participants who participated in the study. Participants' ages ranged from 25 to 54 years $(\mathrm{m}=36)$. There were 4 males and 5 
females. Diagnoses included Schizophrenia (5), Bipolar (1), Schizoaffective (1), Major Depression (2). Average length of illness was 21 years.

\section{$\underline{\text { Research Method }}$}

Qualitative data. A hermeneutic phenomenological method guided the qualitative component of this study. Hermeneutic phenomenology attempts to find, describe, and understand the individual's subjective experience by systematically determining the invariant components of a particular phenomenon, e.g. be-ing a person who is African American with SPMI (Davidson et al, 1997, 2003; Giorgi, 1985, 1987; Van Manen, 1990). The phenomenological approach is congruent with the recovery perspective, which must stay 'near' the lived experience of severe mental illness (Davidson, 2003). Although phenomenological research seeks the essence of the experience, there is the realization that the interpretation of that experience is socially constructed by the participants themselves and co-constructed with the researcher.

Qualitative data were collected at three time points (6 months, 12 months, and 18 months after initial contact with MHR) using semi-structured interviews that were audio taped verbatim and transcribed. Interviews lasted one to two hours. Each interview focused on five questions: What are your life aspirations? How does participation in MHR services help you achieve your goals? What do you do that helps you achieve your goals? What obstacles do you experience in recovery? What do you need that you don't have that would help you in recovery?

Phenomenological data analysis was guided by the Afrocentric paradigm (Reviere, 2001; Schiele, 1997; 2000; Schreiber, 2000), which is a constructive view of African American behavior that incorporates the centrality of African ideals and values 
(e.g. interdependency, collectivity, spirituality and affect) and the American experience of oppression as a valid frame of reference for examining data. Themes were assigned and clustered based on a line-by-line and holistic reading of interview transcripts as well as across-case comparisons. Essential themes were determined using the process of imaginative variation (Girogi, 1985, 1997). Imaginative variation is a process whereby the researcher takes a concrete example of a thing, and imaginatively subtracts one feature, then another, discovering in the process which features are essential and which are not. A qualitative computer research program (Atls-ti) was used to recode the transcripts according to the essential themes and retrieve the quotes to substantiate and describe the findings. The findings were validated by repeatedly reading and testing texts against proposed interpretations.

Since qualitative research uses the researcher as the instrument of data collection and the center of the analytic process (Patton, 1990), it is necessary to establish mechanisms that hold the researcher accountable for the disciplined use of her subjectivity. The interviewer was White and kept an audit trial of raw data as well as a $\log$ of experiences, emotions, insights and questions.. Analysis was done by a White researcher and reviewed by a White consultant who 'shadowed' and challenged the research process by reviewing the findings against the associated quotes from transcripts.

\section{TO THE CONSULTANTS: Please review and comment of the description of how}

you are identified. The final manuscript was reviewed by four African American consultants. Three of the consultants were researchers with backgrounds in mental illness and AIDS. The final consultant was a clinician who works with SPMI clients in recovery. 
Quantitative data. Quantitative data was collected at three time points (6 months, 12 months, and 18 months after initial contact with MHR) on demoralization, engulfment and coping. Demoralization was measured by the Psychiatric Epidemiology Research Interview Demoralization Scale (PERI-D) (Dohrenwend et al., 1980). The PERI-D is a 27-item instrument that uses a 5-point Liker scale. Reliability and validity tests of the PERI-D in the United States have shown satisfactory results. Reliability was found to be high as well in an assessment that used data from a triethnic (White, African American and Mexican American) sample of community residents (Vernon \& Roberts, 1982 ). Coping was measured by the Mental Health Confidence Scale (Carpinello et al., 2000). The Mental Health Confidence Scale is a 16-item measure of optimism, coping, and advocacy designed to assess the self-efficacy beliefs of persons dealing with mental disorders. It uses a 6-point Likert scale. Coefficient alpha is .94 for the full scale and .90 for the coping subscale. Engulfment was measured by the Modified Engulfment Scale (MES) (McCay \& Seeman, 1998). The MES is a 24-item scale adapted from the Engulfment Scale (Lally, 1988) for use with a psychiatric outpatient population to measure the degree to which a person's self concept becomes defined solely by illness. It uses a 5-point Liker scale. Coefficient alpha is .91.

Analysis of the quantitative data was not performed until after the analysis of the qualitative data was finished.

Results

Qualitative Findings 
Four themes emerged from this study: striving for normalcy, striving for a positive and proactive outlook, mastering the challenges posed by mental illness, and leaning on the supports that watch out for and over me.

Theme 1: Striving for Normalcy. Participants in the study worked hard to survive in and be part of a productive society. They worked to strengthen their commonality with others by pursuing those paths that they knew would make a difference and by striving to prove their credibility to others. A man described what guided his efforts. "Normal people have apartments. I have an apartment. Normal people have a car. I have a car. Normal people have a job. I have a job. Normal people go to church. I go to church. So...I'm trying to get to realism and trying to do what normal people do."

Participants were definitive about what would make a difference in the short run, their dreams for the future and the obstacles that blocked their ability to move forward. They related with a sense of urgency their needs to procure essentials such as permanent housing, sufficient monies, predictable transportation, or job related skills in order to achieve a sense of stability. A man worried about retrieving monies taken out of his check by the government because of help he had received from his mother. "They take my money... and that's why I come here to get help...they gonna help me out.. cause she didn't give me no money like that." A mother talked about needing housing before she could get custody of her children. "[Another goal is] finding stable housing for me and my kids... because I don't have custody of my other children...I would need that so I can get them back and be a family again." The sense of necessity that accompanied these goals was driven in part by not knowing how or where to look for what they needed. 
Participants also wished to be in concert with others. Sometimes this desire took the form of future dreams. "[I want to] get me a girlfriend, somebody who loves me, someone care for me. Get married. Someone [to] help me, cook for me, buy some clothes. I'm still searching. I'm still searching." Sometimes the desire had to do with finding someone who would listen so participants could feel joined in their experience. "I hold things in...If I could talk to people and let it out, I feel more free. That's why you see a psychiatrist. He ask you questions. You talk it out. My psychiatrist don't ask me questions like that... You might feel bad, upset. Ain't nobody to turn to to listen to you, your problems. I talk to myself."

Participants struggled with the obstacles that blocked what they needed. Unpredictable bus transportation or insufficient monies for bus passes, for example, made it difficult to get to school. They felt cornered and frustrated by conditions they could not change. A man's desire to work, for example, was thwarted by the fact that working would reduce his SSI check. "It really leads to a financial bind, you know, to have one or the other ...And you gotta have the check because the disability's involved."

The Afrocentric paradigm stipulates that to achieve equality i.e. to not be treated as different or lesser, the focus must be on sameness or similarity as opposed to differentness (Schiele, 2000). Moreover, sameness can only emerge from an emphasis on inclusion. Participants' strove to be accepted, included and treated as equal by proving their credibility in a variety of ways. Maintaining stability, for example, showed others that participants could manage their own lives. "Before I was not consistent with staying up with my medical health. And that's why my children had got taken from me... So now I'm taken my medication." Some participants worked to prove that they could measure 
up. "Nobody [in my family] has dropped out of school so I have to prove I can finish." Others strove to establish they were responsible and trustworthy. An offender said, : "Every chance I got to go home, I went home. Every chance. And I came right back." In some cases, participants were upset about the number of obstacles they had to jump over. "How many more years do I have to give you people that. To let you know that I'm capable and able to ...deal with life? I mean I'm waiting for an acknowledgment [that I'm] a productive member of society, a human being. And not some kind of labeled number."

Participants' knew what would help them to function as contributing community members and ruminated about the barriers that stood in their way. Even if they were not directly accountable to another person or institution, they felt compelled to reassure people of their good intentions, knowledge base, strength and reliability.

\section{Theme 2: Striving for a Positive and Proactive Outlook. Participants recognized} that their illness left them susceptible to feeling overwhelmed and discouraged. Efforts to remain positive, therefore, were difficult and to be deliberate. People worked to strengthen their resolve by cultivating affirmative attitudes and focusing both on the future and on things outside themselves. No one felt sorry for themselves. Rather participants concentrated on what they were doing in spite of or to counter obstacles to their health.

They felt that their outlook was something that had to be specifically managed to counter negativity. "My mind is the biggest obstacle." "I control myself. My mind. I control my mind." Sometimes that meant actively controlling negative influences from the outside, “Certain TV shows I won't watch because I'll get really depressed." They 
also worked to change their thinking. "If I feel depression coming on, I'll start thinking very positive things and I'll just keep saying it over and over in my mind until it really sinks in." Explaining outcomes in affirmative ways provided reassurance and blocked a potential sense of failure. A woman who did not get high scores on her GED exam said, “After being kind of discouraged, I just figured it was God's way [of] letting me know I was going down the wrong path.”

Participants' focus on things outside themselves provided a structure that supported their movement. "My kids [motivate me] to go out and do something...rather than sitting in the house all the time." "I'm not in the house by myself. I have a cat to look after.” Regularity in structure helped. "Getting up every morning...I'm gonna get up and walk around." Participation in meaningful activities did too. “"'I make sure I go to church and I'm active in my church." "I got a band. This guy...I be teachin' him. I know music.

Participants also kept optimistic by looking forward and building resolve. In some ways, they served as coaches to themselves about what matters. . "I'm gonna be entering a program called Pathways pretty soon. They're gonna be offering that kind of thing (part-time work). The money isn't as great as it could be but the learning experience is." Looking forward required being open to new things. "I was just doing whatever my pastor felt was good for me, like therapy or whatever she said. I mean I let my pride go and just did it because I wanted to be healed." Participants built hope by prodding themselves to stay the course. " The more I do it (life), the better I get at it. You know, practice, practice, practice. Life is like that." They also warned themselves not to give into defeat. A woman who did self-cutting said, "This was just a downfall but 
it will never happen again. Cause once you make up in your mind that this is something you're no longer gonna do, this is no longer an option for me."

Working against discouragement had its ups and downs. "Up and down all the time... Sometimes I just don't want to be bothered and I kinda close people out." Accepting the relentless nature of the struggle, however, fortified participants against the toxicity of an inferiorization process that might contribute to mental disorders in African Americans (Schiele, 2000). People buoyed themselves against a sense of personal failure by controlling what entered their minds, countering avoidance, and challenging mindsets that could undermine confidence. Along with encouragement from others, these mechanisms helped them experience life as more manageable and upbeat.

Theme 3: Mastering the Challenges Posed by Mental Illness. Participants faced a variety of challenge s to meeting their basic needs, managing stress, making decisions, getting support, and feeling competent. They found that being persistent with a goal in mind and patient while actively waiting helped them stay the course. They also had to contend with an ever present sense of uncertainty and danger which they managed, in part, by noting their accomplishments.

Whatever the effort, persistence was a routine response to challenges. Participants expected that they would have to work harder, be more focused, try again after failing, and do things they disliked. People described a sense of routine that grew out of needing to be persistent. "It's a struggle. I gotta cook, and gotta wash, and I gotta take care of the cat. I gotta maintain my own physical hygiene at all times." Persistence also meant being strong by enduring conditions they could not change. A man talked about tolerating an onerous work environment . "So I stuck with this job because I need 
to work, to get out in society, to feel like a person [instead of] some fool just out there trying to do nothing for himself." Participants commonly calculated or reconfigured options in order to stay the course. A woman with both schizophrenia and diabetes figured her options in case she relapsed again. "I'm not old enough to be in a nursing home, cause I ain't that bad but if I [get] worse, I decided to go to the McGoo building cause they can feed you down there." Being persistent also meant accepting the slow nature of change. When asked how things were going, one man said, "Same goals. Same goals. Slow. Slow.”

Participants used active waiting as another way to manage circumstances over which they had little or no influence. Active waiting involved biding time while remaining future oriented and focused on the goal. It also required being patient in spite of discomfort and avoiding cynicism in the long run. As one man said, "I got power. Sit and wait." Although participants frequently referenced waiting for school to begin or waiting to find work, active waiting more often meant preparing for an indeterminate future. "I would get myself prepared [for welfare to end] cause I know it's coming. And I gotta be ready emotionally, physically, all that." Having to postpone what they wanted also required the ability to suspend time. Participants gave themselves explanations to instill tolerance and optimism. "It's like you wait so long but it's like 'Okay God, I'm gonna wait for you so everything is in your timing."' A man reiterated what his brother had told him. "Things get greater later."

Managing their mental illness meant that participants had to learn what was too little or too much, take small steps and do things gradually, help others recognize their needs, and create optimal challenges. Some people struggled with but accepted the 
realities imposed by their illness. Others changed directions as they weighed and measured what they could realistically expect of themselves. A man decided against becoming a welder. "I can make the carpentry work for me a lot better. See 'cause the welding, you end up going on these construction sites or factories. But for carpentry, I can be my own boss...And that's gone help me keep the stress level down." People also had to deal with the differences between what they themselves or others thought they could do. A man diagnosed with bipolar disease, shared how his conflict with treatment staff resulted in overshooting the mark. "They kinda want you to set your goals...for a lower form of self-esteem..and it just makes everything worse in the end...So what you do is you try to over reach your standard and that's when things kinda get a little mixed up." People also recognized that they needed to proceed slowly. A woman who was a Jevohah's Witness said, “I passed out magazines. And that was preparing me for being able to stay on my own. Then one day I ventured out from the hospital and I decided I could do it...And I just started going further and further away." People also recognized their need for challenge. "Walking around aimlessly is stress for me."

Participants contended with a sense of ever-present danger shadowing the issues of survival, safety and comfort. Money never stretched far enough. Housing was rarely adequate. Public transportation was unpredictable. In many instances, however, participants' behavior was monitored by governmentally regulated social institutions that made them feel significantly more vulnerable. "If I don't find housing, it'll be more moving around a lot . So [by] my not being stable and moving around a lot I might not be able to get my kids." A man who was on parole felt endangered because his case manager monitored his live-in relationship with a woman. "He told me she can't stay 
with me. ..We went down to a meeting and they had the U.S. marshals there [who said] 'What we are getting ready to tell you is kind of hard so we thought we might have these people here to ensure each other's safety.' I can't understand why they wanna do that to me. ...[A]m I going to be alone the rest of my life? That's scary." Even after being released from a civil commitment, a man reminded himself that his freedom was not assured. "'It's one thing to get your freedom. It's another thing to keep it."

Participants also had to figure out how to manage physically dangerous situations. A man befriended his attacker as his way to bargain for future safety after being hit by the man with a bat. The attacker said, "'If you don't give me [your money], I'm gonna hit you again.' I said, 'Put that bat down! You come [to] my house. Take me back home.' I got in his car, took me home, and I let him in my house. [I said,] 'My house is your house.' He walked out... If he see me walking the street, he'll turn and go on the other side. His conscience.” People's experiences had overtones of oppression and nonspecific discrimination. It was difficult to ascertain if reactions from others were due to having mental illness or being Black, homeless, or an ex-offender. A women who confronted a receptionist said, "Is it a problem with my skin color or because I have mental health issues. Which is it?" Although participants expressed that they felt hounded by forces that regulated opportunity and monitored their behavior, interfered with their efforts to establish stability, or threatened to take things from them, these circumstances, though maddening, were not surprising. They just made the job harder.

Participants dealt with uncertainty by marking progress. Their past successes showed them they could do it again. A man who had had a positive group experience used it as a model for what he wanted now. "In these groups ... were people who were 
cops, who were lawyers. There was one guy [who] was a traffic engineer...They continued their lives to where they didn't have setbacks." People frequently noted movement up the ladder by talking about time or making downward comparisons with themselves. "No crying spells for six months." "I made a complete transformation from what I was like when May came to where I'm at now." "I've been out here for two years now." They identified what they had done that made the difference. "'I've been really efficient with the money." "This time it was pretty easy. I just kept...I was determined, so I kept looking every day." “Anything that was not righteous or Godly, I gave it up." Participants recognized that overcoming obstacles increased their options. "I could catch the bus, but I didn't know how to go back home. That's why I stayed seven years at Thorn Avenue and never left, never went downtown... So I learned something new from my daughter and it's nice being able to get around again. To be able to have a real bus pass and use it and enjoy yourself."

Noting accomplishments produced pride and served to strengthen self worth and identity. What they had attained was theirs and served to build a safety net as a hedge against relapse.

Despite the never-ending uncertainties and consequences of their mental illness, participants, for the most part, remained steadfast in their belief that a better life was possible. They demonstrated this by their perseverance, efforts to patiently endure obstacles and set backs, proactive problem solving and rationalization of their life, and the conviction that, in spite of their condition, they were human and belonged in the larger, every-day world. 
Theme 4: Leaning on the Supports that Watch Over and Out For Me. Participants were bolstered by supports that felt comforting, secure and familiar. They included God and involvement in church, family members, or case managers and other mental health professionals. Sources of support were also sources of strength so that otherwise formidable challenges became doable.

Nearly all participants had enduring relationships with God or their church. They emphasized the unity between themselves and God thereby showing that God is subjectified or internalized which is consistent with traditional African philosophical thought (Schiele, 2000). "I'm with the Lord. I'm with God. I work for Jesus." Participants spent time talking with God and leaned on prayer to endure hardships. "Sometimes I have bad days, bad nights, that I have to pray harder than normal people would, just to keep my sanity." Talking with God, however, was a two-way relationship. "God...knows my heart, my mind, my thoughts, my issues. I talk to him. And he makes plain to me everyday that he is blessing me.”. People used other religious avenues as well to provide structure and support for their recovery. A man described how he used church related activities to build social skills. "I volunteered to...help out with the Bingo. I did that for a whole month. And then I signed up for the social justice board at church. I started that. And than last Saturday I was in the Easter play. So I've been getting out more, but mostly with the church." A woman with Major Depression described using encouraging videotapes of evangelists, positive scriptures, and Bible study. Participants also took direction and persuasion from religious leaders. "She's a down to earth person where if you really [are] going thorough [a lot], you can call her and say, 'I'm going through [a lot].' And she'll say, 'Well what do we need to do to fix it?'” 
Participants did not view themselves as independent of or separate from their families. Rather the concept that 'we're in this together' was central and meant both that family was a source of support and mutual obligation and also a group to which they were accountable. This interconnectedness showed in several ways. Recovery for women was tied up with the wellbeing of their children. A mother described her commitment to her eighteen year-old daughter. “I won’t let her go nowhere. I gotta keep her with me until she be ...ready to push out." Another mother made arrangements for her aunt in Pennsylvania to take custody of her children. "If they're there with her, I know they're in a safe place and I can always come to visit and talk to them and stuff." People kept family current in their thinking and planning even if family members lived far away. "I'm on my way back. I'm going back. I got people there. I plan on goin back to my momma. That my home town." Most of the men dreamt of having a future family. "That's what I pray at night. Let me get a girl. Laying next to you in bed. Two minds stronger than one...If she have three kids and they ain't mine, I still help her." Family members also gave direct help so participants could meet their needs. A mother typed her daughter's papers for school. A sister fixed meals for her brother. A grandmother gave her granddaughter money to help her buy a car. A woman described the intricacies of family interdependency, "It's kind of hard to get on the bus with two kids and then I didn't have a stroller either. So it's helpful when [my mom] comes by to give me a ride. That way I don't have to drag both of them out. So she'll either watch the one while I go and I'll take the other one or something like that." Participants felt grateful for the backing. A man described how his mother's giving motivated him to 
attend school. "I just think about how much she paid out and so I get up and go to school."

Participants viewed particular case managers, their agencies, and other mental health professionals as vital supports for their health and made full use of their services. They readily distinguished those who were helpful or went the extra mile from professionals who did little to help them or were impediments. Those case managers who were notable made it possible for people to function independently. "They helped me with moving expenses and gave me a voucher to Catholic Charities for the sofa and stuff." "He done good. Found me an apartment. I ain't never had an apartment." Generally case managers were seen as approachable and participants used them in a variety of ways. 'I'm not afraid to call her and say, 'You know what? I'm feeling discouraged right now or I need your help just being on the right track." A man who felt he should get out more said, "They come and we sit down and chit chat and I entertain. To me they're more like my social outlet." Participants noted case managers' attitudes. "She let me take control of my problems. She wasn't dominant." "She don't overstep her boundaries but she gives me her opinions." Indeed, some participants referred to their case managers as friends. Relationships had a feeling of mutuality and participants felt that case managers worked for them. For example, a man admonished his case manager for expecting too much. "He told me to call the Housing Authority. I can't talk to them. That's his job to talk to them.. He got more power than me. I can't call on these people and be talking about [housing]." Case managers or other mental health professionals were seen as resources that stuck by them, believed in them and covered them from behind. Regardless of whether contact was regular or sporadic, participants 
took their presence for granted. 'He's on an ongoing basis. He's just, he's like a part of my life."

Participant leaned on or protectively held up others who were psychologically integrated into their journeys. Even people who identified themselves as loners experienced God personally or carried dreams or memories of close family ties. Whether or not they were physically present, people looked upon their supports as psychological guardians.

\section{Quantitative Findings}

Data were analyzed with paired t-tests on the dependent variables of demoralization, coping, and engulfment. There was a significant change in reduction of demoralization from Time 1 to Time $2(M=71, S D=2.99, t=2.99, p=.03)$ and a significant improvement in coping from Time 1 to Time $2(M=2.67, S D=2.58, t=2.53$, $p=.05)$. There was no significant change in engulfment.

\section{Discussion}

The Afrocentric paradigm calls for a perspective that offers a constructive rather than deficit view of African-American behavior (Akbar, 2000; Schiele, 2000). Moreover, it calls upon human behavior and social events to be interpreted from the particular worldviews of people of African descent. Finally, it demands that research done from the Afrocentric paradigm provide some immediate applicability to the resolution of problems created by conditions of sustained oppression.

This study begins to give some understanding, from the consumer's perspective, of the experience and process recovery for African Americans with SPMI. Participants strove to be positive and proactive, used varied and complex coping strategies, and 
developed good relationships with case managers. Indeed, the nature of their involvement with community, family and church as well as the role of social issues, e.g. probation, homelessness, poverty, discrimination adds new information to the literature on the experience of recovery. Although some of the results are similar to previous findings, they take on new meaning as a result of the African American experience. For example, the social stigma associated with mental illness is frequently referenced in the literature, e.g. Davidson et al, 2001. In this study, however, participants described being treated poorly but did not talk about stigma specific to mental illness. Indeed, it may have been difficult for them to distinguish whether reactions from people who were not African American were predicated on race or mental illness because these people could be responding prejudicially to both conditions. Also, living with the reality of oppression may not make discrimination, that is specific to mental illness, feel particularly unique.

Although the Afrocentric model is compatible with phenomenology (Reviere, 2001), the relationship, in this study, between qualitative and quantitative approaches is particularly useful because data from both methods were in support of each other. Specifically, the reduction in demoralization between Time 1 and Time 2 was substantiated by the efforts participants made to counter hopelessness by intentionally striving to build a positive and proactive outlook. They also used persistence and active waiting to manage feelings of discouragement.

The lack of change in engulfment may have been influenced by having to deal relentlessly with circumstances that left them feeling endangered and uncertain. Alongside their general efforts to move forward, participants found it particularly difficult to move outside of circumstances over which they had little or no control, i.e. 
getting children back, lack of housing, living in dangerous neighborhoods. In that context, the threat of relapse comprised just one of many disempowering circumstances. Findings on the stability of engulfment over time may also reflect the length of time they had been living with mental illness $(\mathrm{m}=21$ years).

The increase in coping between Time 1 and Time 2 was confirmed by the fact that participants used a myriad of strategies to endure and surmount challenges. Participants persevered by being persistent and cultivating a patient but expectant attitude. They regularly figured and reconfigured options to increase possible solutions to problems. Their recognition of what they had already done reinforced their progress and gave access to knowledge about the previously successful strategies they had used. Participants sought allies using family members, clergy, and case managers as resources for meeting both physical and psychological needs.

The combination of qualitative and quantitative data was useful because it identified the significance of the increase in coping and decrease in demoralization and the narrative data gave examples of the mechanisms that influenced improvement between Time 1 and Time 2. These changes are noteworthy as participants averaged 21 years of illness. Further research should focus on the factors that influence these kinds of changes.

These findings have implications for practice and improving recovery-oriented services to African Americans. In this study, participants clearly stated what they needed to move forward and assiduously pursued their goals. Participants responded positively to collaborative and personalized relationships with mental health professionals and others who put them in charge of directing what they needed, respected their requests or 
asked directly what they could do to be of assistance. Participants had a variety of strategies to deal with obstacles. Case managers could activate and help clients access this wealth of knowledge by asking them to describe how they managed situations in the past and what they are doing in the present. Active waiting is a particularly important strategy for case managers to note and respect because it has the potential to build patience and reduce discouragement. Finally, case managers need to consider mental health stigma and anti stigma interventions that are inclusive of racial discrimination and expand their cultural sensitivity to include the sense of endangerment experienced by African American clients.

This study was limited to the lived experience of African Americans in the upper Midwest. It needs to be replicated with a larger sample from different geographical locations. The research team would need to include African Americans. Moreover, case management could be informed by future studies that examine the impact on recovery of dealing with people in power positions, e.g. case managers, psychologists, administrators. In this regard, future studies could also include measures of cultural mistrust to be administered over time.

Several procedures used in this study offer ways to strengthen methodological rigor in qualitative and mixed methods research. Qualitative results were not influenced by the quantitative findings because they were determined independent of and preceding the analysis of the quantitative data. Their trustworthiness was enhanced, therefore, both by the lack of contamination and the fact that the quantitative data strongly supported and reflected the qualitative results. 
TO THE CONSULTANTS: This is an example of what we would say if your feedback is similar and supportive. This is also where we would put feedback if it raised questions about the methodology, findings or anything else. Reviere (2001) contends that inquiry must be validated by using Afrocentric research scholars to review and critique the inquiry and interpretation of data. Three Afrocentric research scholars and an experienced African American clinician reviewed the study. Their critiques informed the research discussion.

This study was limited by the fact that the results cannot be generalized beyond the participants who comprised the sample for this research or the sociohistoric time when they were interviewed. The lack of African American researchers on the team means that findings must be accepted with caution. The European American perspective of the researchers influenced and limited the questions and probes used in the interviews, reactions from participants, and understanding of the data. 


\section{References}

Akbar, N. (1998). Afrocentricity: the challenge of implementation. In J. D. Hamlet (Ed.), Afrocentric visions: Studies in culture and communication. Thousand Oaks, CA: Sage

Alvidrez, J. (1999). Ethnic variation in mental health attitudes and service use among low-income African Americans, Latina and European American young women. Community Mental Health Journal 35: 515-530.

Bae, S., Brekke, J.S. \& Bola, J.R. (2004). Ethnicity and treatment outcome variation in schizophrenia: A longitudinal study of community-based psychosocial rehabilitation interventions. The Journal of Nervous and Mental Disease, 192, 623-628.

Baker, F.M., Stokes-Thompson, J., Davis, O.A., Gonzo, R., \& Hishinuma, E.S. (1999). Two-year outcomes of psychosocial rehabilitation of black patients with chronic mental illness. Psychiatric Services, 50, 535-539.

Bradshaw, W., Roseborough, D., \& Armour, M.P. (in press). Lived experience of recovery: The initial phase of treatment. Psychiatric Rehabilitation.

Carpinello, S. E., Knight, K.L., Markowitz, F.E. \& Pease, E.L. (2000).

The development of the Mental Health Confidence Scale: A measure of selfefficacy in individuals diagnosed with mental disorders. Psychiatric Rehabilitation Journal 23, 236-243.

Chinman, M., Allende, M., Bailey, P., Maust, J. \& Davidson, L. (1999a). Therapeutic agents of assertive community treatment. Psychiatric Quarterly, 70, 2, 137-162.

Davidson, L. (2003). Living outside schizophrenia: Qualitative studies of recovery in schizophrenia. New York: New York University Press.

Davidson, L. \& Strauss, J. (1992). Sense of self in recovery from severe mental illness. British Journal of Medical Psychology, 65, 131-145.

Davidson, L., Stayner, D., Lambert, Slk smith, P. \& Sledge, W. (1997). Phenomenological and participatory research on schizophrenia: Recovering the person in theory and practice. Journal of Social Issues, 53, 767-784.

Davidson, L., Stayner, D.A., Nickou, C., Styron, T.H., Rowe,M. \& Chinman, M.L. (2001). "Simply to be let in": Inclusion as a basis for recovery. Psychiatric Rehabilitation, 24, 375-388. 
Dohrenwend B.P., Shrout P.E., Egri G., \& Mendelsohn F.S. (1980). Nonspecific psychological distress and other dimensions of psychopathology: Measures for use in the general population. Archives of General Psychiatry 37, 1229-1236.

Estroff, S. (1989). Self, identity and subjective experiences of schizophrenia: In search of the subject. Schizophrenia Bulletin, 15, 189-196.

Giorgi, A. (1997). The theory, practice, and evaluation of the phenomenological method as a qualitative research procedure. Journal of Phenomenological Psychology 28 , 235-260.

Giorgi, A. (1985). Sketch of a psychological phenomenological method. In A. Giorgi (Ed.), Phenomenology and psychological research. Pittsburgh: Duquesne University Press.

Jacobson, N., \& Greenley, D. (2001). What is recovery? A conceptual model and explication. Psychiatric Services, 52, 482-485.

Lally, S.J. (1989). "Does being here mean there is something wrong with me?" Schizophrenia Bulletin, 15, 253-265.

Lysaker, P.H., Campbell, K., \& Johannesen, J. K. (2005). Hope, awareness of illness, and coping in schizophrenia spectrum disorders: Evidence of an interaction. Journal of Nervous \& Mental Disease, 193, 287-292.

McCay, E., \& Seeman, M. (1998). A scale to measure the impact of a schizophrenic illness on an individual's self-concept. Archives of Psychiatric Nursing, 12, 4149.

Patton, M. Q. (1990). Qualitative evaluation and research methods. Newbury Park, CA: Sage Publications.

Phillips, E.S., Barrio, C. \& Brekke, J.S. (2001). The impact of ethnicity on prospective functional outcomes from community-based psychosocial rehabilitation for persons with schizophrenia. Journal of Community Psychology, 29, 657-673.

Reviere, R. (20010. Toward an Afrocentric research methodology. Journal of Black Studies 31, 709-728.

Schiele, J. H. (2000). Human services and the Afrocentric paradigm. New York: Haworth Press.

Schiele, J.H. (1997). The contour and meaning of Afrocentric social work. Journal of Black Studies, 27, 800-819. 
Schreiber, L. (2000). Overcoming methodological elitism: Afrocentrism as a prototypical paradigm for intercultural research. International Journal of Intercultural Relations, 24, 651-671.

Spaniol, L., Wewiorski, N. J., Gagne, C., \& Anthony, W.A. (20020. The process of recovery from schizophrenia. International Review of Psychiatry 14, 327-336.

Telles, C., Karno, M., Mintz, J., Paz, G., Arias, M., Tucker, D., \& Lopez, S. (1995). Immigrant families coping with schizophrenia: Behavioral family interventions with a low-income Spanish speaking population. British Journal of Psychiatry, 167, 473-479.

The President's New Freedom Commission on Mental Health. (2003). Achieving the promise: Transforming mental health care in America. Final report. Rockville, MD: U.S. Department of Health and Human Services.

U.S. Department of Health and Human Services. (1999). Mental health: A Report of the Surgeon General. Rockville, MD: U.S. Department of Health and Human Services

Van Manen, M. (1990). Researching lived experience: Human science for an action sensitive pedagogy. London, Ontario: State University of New York Press.

Vernon, S.W. \& Roberts, R.E. (1981). Measuring nonspecific psychological distress and other dimensions of psychopathology. Further observations on the problem. Archives of General Psychiatry, 38, 1239-1247.

Williams, C.C. \& Collins, A.A. (1999). Defining new frameworks for psychosocial intervention. Psychiatry 62, 61-78.

Wisconsin Blue Ribbon Commission on Mental Health (1997). Wisconsin Blue Ribbon Commission on Mental Health: Final report. Madison, WI: State of Wisconsin, Office of the Governor. 
